\title{
Aspectos etiopatogénicos del asma bronquial en el niño
}

\author{
DR. GONZALO govez A. *. SERgIO IBANEZ O. **.
}

1.- Introducción. Por más de 60 años, desde que Meltzer notó la similitud del asma humana con la anafilaxia en el cuy sensibilizado, los alergistas enfatizaron en la importancia de una hipersensibilidad de tipo inmediato en la etiopatogenia de este sindrome (1).

Rackemann y Cooke observaban que no todos los casos de asma eran atribuibles a alergia, y para estos casos hablaban respectivamente de "Asma intríseco" y de "Asma no-sensitivo" (1).

1.1.-- Definición. La más adecuada nos parece la formulada por la American Thoracic Society" en 1962: "Asma es una enfermedad caracterizada por una reactividad aumentada de tráquea y bronquios ante varios estímulos, y que se manifiesta por una obstrucción difusa de las vías aéreas que remite su severidad ya sea espontáneamente o como resultado de medidas terapéuticas" (2).

1.2.- La diátesis atópica. Según Coca el concepto de Atopía era el de un estado de hipersensibilidad inmunológica propio de los seres humanos y adquirido espontáneamente a través de una influencia hereditaria. Posteriormente los detalles de este concepto fueron cambiados a la luz de las investigaciones inmunológicas (3). Usamos el concepto en el sentido de que el defecto se fundamentaría en un estado alterado del terreno.

Las características del paciente portador de una Diátesis Atópica han sido estudiadas: la alta incidencia $(50 \%)$ de dermatitis atópica en niños asmáticos; dermografismo alterado en la piel de estos niños; palidez a veces acentuada de la piel con mucosas muy rojas; tendencia a la sudoración profusa, a veces como pródromo de una crisis

* Servicio de Broncoptlmonares, H. Calvo Mackenna, Area

*w Jrjente. Servicio Broncopulmonares. Prof. de Pediatría. Hosp. Caldo Mackenna. asmática; excesiva producción de mucus en el tracto respiratorio $(4,5)$. Evidencia de antecedentes familiares de alergia se encuentran en $40-80 \%$ de los niños asmáticoss según diversos autores (6-7), en nuestra experiencia este antecedente to hemos encontrado en alrededor de un $75 \%$ de los casos.

2.-Aspectos etropatogénicos. Analizaremos varios factores que están involucrados en el desencadenamiento de los mecanismos que producen los síntomas obstructivos del Asma Bronquial. Recordemos que los mecanismos básicos son: contracción de la musculatura lisa de bronquios y bronquiolos, edema y congestión de la mucosa, y secreción de mucus.

\section{1.- Alergia e hiperreactividal bronquial.}

Usamos el término de alergia para referirnos a una reacción inmunológica de tipo inmediato (Hipersensibilidad Hiperinmune de tipo I de Gell y Coombs).

Las reacciones atópicas en el hombre incluyen la sensibilización a substancias usualmente inocuas (alérgenos) por una puerta de entrada natural (respiratorja, digestiva o piel). Se sintetiza un antícuerpo específico o "Reagina" ( $\mathrm{gEE}$ ) que se adhiere a la superficie de células cebadas o basófilos en el "Organo de Choque", tomando la condición de células sensibilizadas. Al unirse al antigeno se desencadenan una serie de reacciones bioquímicas dentro de la célula que conducen a la liberación de medjadores químicos (Histamina, SRL-A, Bradiquinina, Scrotonina), que a su vez van a cjercer su acción en los diversos efectores del "Organo de Choque" (en este caso es el árbol bronquial). (7-8). 


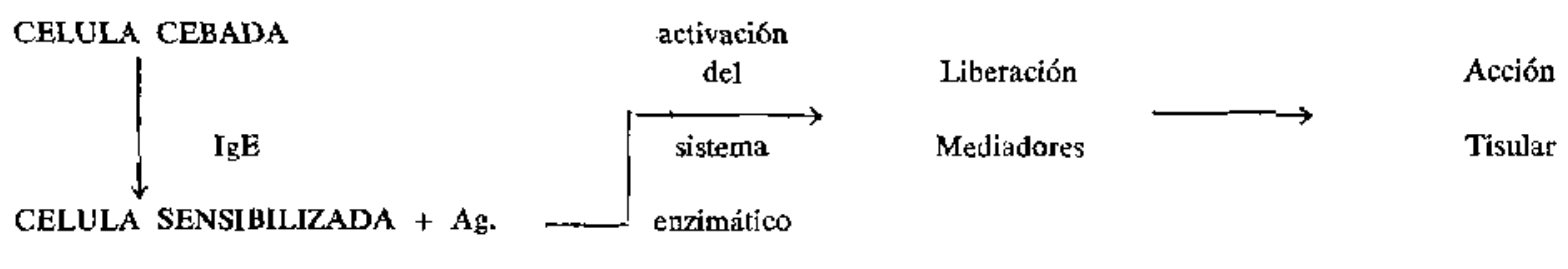

Numerosos trabajos de investigación informan que además de la existencia de anticuerpos ( $\mathrm{IgE}$ ) especificos, hay elevación de las concentraciones de IgE en sujetos alérgicos. (9-10). Sin embargo, la demostración de reaginas en individuos normales, el becho de que en poblaciones bajo idéntica exposición antigétrica sólo algunos individuos manifiesten alguna forma de hipersensibilidad, y que de estas sólo algunas se refieran al árbol bronquial, hacen aparecer como muy vago el concepto de "Organo de Choque". De tal modo que no puede adscribirse el Asma solamente a los conceptos inmunopatológicos (3). Debemos reconocer eso sí que el mecanismo de hipersensibilidad de tipo I juega un importante papel dentro de la etiopatogenia del Asma bronquial (10).

2.2.- Mediadores químicos e hipereactividad bronquial. La inhalación de soluciones atomizadas de Histamina prođucen una leve constricción bronquial en individuos normales, pero asmáticos testeados en forma similar manifiestan una acentuada reacción. Tiffeneau ba demostrado que esta hiperreactividad frente a Histamina puede ser aumentada por infección, sustancias irritantes, estímulos psicológicos (7).

Por otra parte si la enfermedad es de reciente instalacion esta hiperreactividad puede no ser demostrada. Si bien es cierto que la hiperreactividad del asmático ante los mediadores químicos es un hecho establecido, no está claro si es un fenómeno secundario condicionado por el asma mismo o si se trata de una característica primaria (3).

2.3.- Factores fisicos e hiperreactividad bronquial. Frecuentemente el paciente asmático señala como factor precipitante de sus molestias asmáticas la exposición al frío, viento, olores irritantes, gases, humo, etc. Esto se ha atribuido a un mecanismo de reflejo colinérgico inducido por la estimulación de receptores suceptibles o irritados de la vía aérea (3).

2.4.- Ejercicio e hiperreactividad bronquial. El aumento de la resistencia de la via aérea después del ejercicio es significativamente mayor en asmáticos que en normales. El asmático presenta frecuentemente broncoespasmo inducido por eI ejercicio físico. La respuesta puede ser bloqueada por lil administración previa de Simpaticomiméticos o Xantinas, y parcialmente con Ia administración de Corticoides o stigestión hipnótica; no así con la administración de antihistamínicos.

Se ha pensado que la hipoxia o la hipercapnia actuarian, o tal vez mecanismos de tipo reflejo; pero aún no se ha logrado precisar claramente el mecanismo involucrado.

2.5.- Factores psicosomáticos. Aparentemente debe existir primariamente un sustrato somático de hiperreactividad bronquial, sobre cl cual podríin actuar posteriormenie los mecanismos psicosomáticos $(3,7)$.

2.6. - Función beta adrenérgica e hiperreactividad bronquial. Los receptores alfa producen broncoconstricción baio la acción colinérgica y por la norepinefrina. Los receptores beta producen broncodilatación, son estimulados por epinefrina e isoproterenol. En los bronquiolos hay ur $90 \%$ de beta receptores y sólo un $10 \%$ de alfa receptores. En cl individuo normal se encuentran en un estado de equilibrio (3-8).

Experimentalmente el bloqueo farmacológico de los beta receptores induce en los asmáticos una severa obstrucción y un aumento de la reactividad a los mediadores (Sly). En Riníticos alérgicos o nacientes portadores de fiebre del heno el bloqueo farmacológico aumenta la sensibilidad bronquial a los alérgenos y mediadores. Sin embargo este bloqueo farmacológico de los beta receptores efectuado en normales no produce el efecto descrito en las experiencias anteriormente citadas. Según estas experiencias el asmático adquiriría con mayor facilidad el bloqueo beta en comparación al no atópico (3).

Sutherland y Róbinson precisaron que epinefrina cstimula la acción de la enzima adenil-ciclasa (beta receptor) que cataliza la conversión de ATP a 3'5' AMP cíclico. La activación de 3'5'AMP cíclico inicia una actividad metabólica de glicogenolisis y lipolisis, produciéndose la relajación del músculo liso por esta activación. Los corticoides potencian esta acción de la epinefrina. El 3'5'-AMP cíclico es catabolizado por la fosfodiesterasa a 5'-AMP inactivo. La Teofilina inac- 


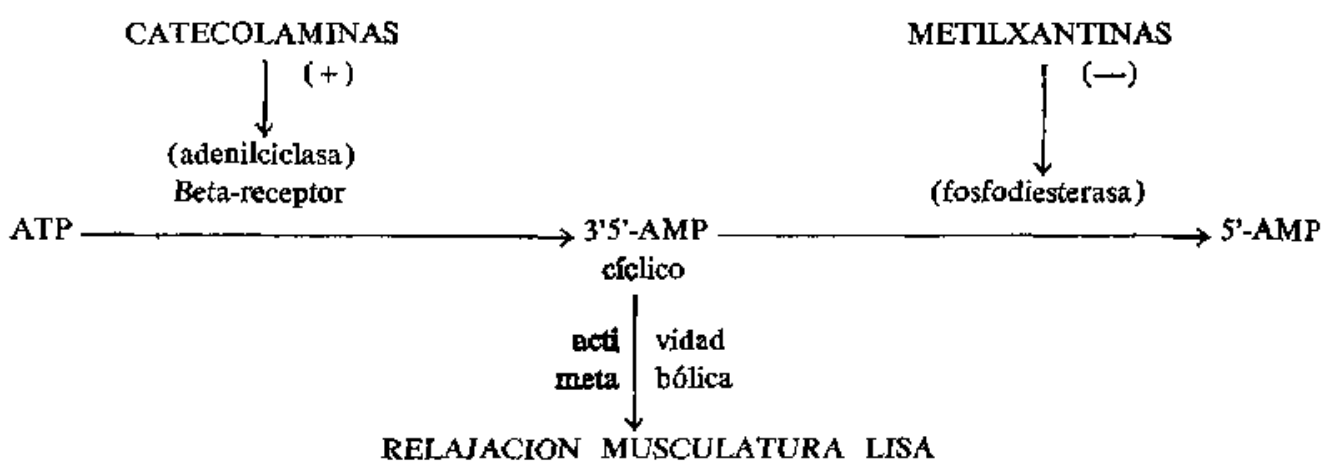

tiva a la fosfodiesterasa, impidiendo una baja de 3'5'-AMP cíclico y de este modo refuerza la acción de epinefrina en mantener un nivel celular alto de 3'5'-AMP cíclico activo (8).

Szentivanyi propuso que el defecto básico en el asmático sería una cantidad deficiente o una alteración de la función de la adenilciclasa, lo cual acarrearía un deterioro de la función beta adrenérgica a nivel bronquiolar. Esto se traduciría en marcada tendencia a la broncoconstricción frente a mediadorcs químicos, estímulos físicos, infección, etc., (12).

A partir de los trabajos de Lichtenstein (13) y de Smith y Parker (14) se puede deducir que un aumento en la concentración de 3'5'-AMP cíclico inhibiría la liberación de histamina en los pacientes atópicos. Se puede también concluir que la reacción antígeno/IgE fija a la célula, activaría al sistema enzimático intracelu]ar liberándose mediadores químicos que producen su acción tisular; esta liberación de mediadores estaría regulada por la concentración de AMP-3,5, cíclico in- tracelular, un aumento de esta concentración inhibe la liberación y una disminución de 3'5'-AMP cíclico aumenta o favorece la liberacjón de mediadores $(1,8,11)$.

3.-Infección y Asma. Numerosas investigaciones ban hecho concluir que la infección respiratoria puede inducir broncoespasmo por mecanismos no-inmunológicos. El testeo cutáneo con extractos bacterianos, así como el testeo de provocación bronquial inhalatorio, no han reflejado especificidad y sus resultados pueden considerarse ambiguos.

Actualmente habría cierta evidencia de que un tipo de hipersensibilidad intermedia mediada por anticuerpos precipitantes (tipo III) podría jugar un papel etiopatogénico en el asma. Esto se ha planteado a partir de los trabajos de Pepys en Aspergilosis pulmonar alérgica $(7,9,10,11)$.

4.-. Asma intrínseco. Existe un grupo de niños asmáticos en los cuales los mecanismos alérgicos etiopatogénicos no se logran precisar, o bien los

CELULA CEBADA

IgE

CELULA SENSIBILIZADA + Ag.

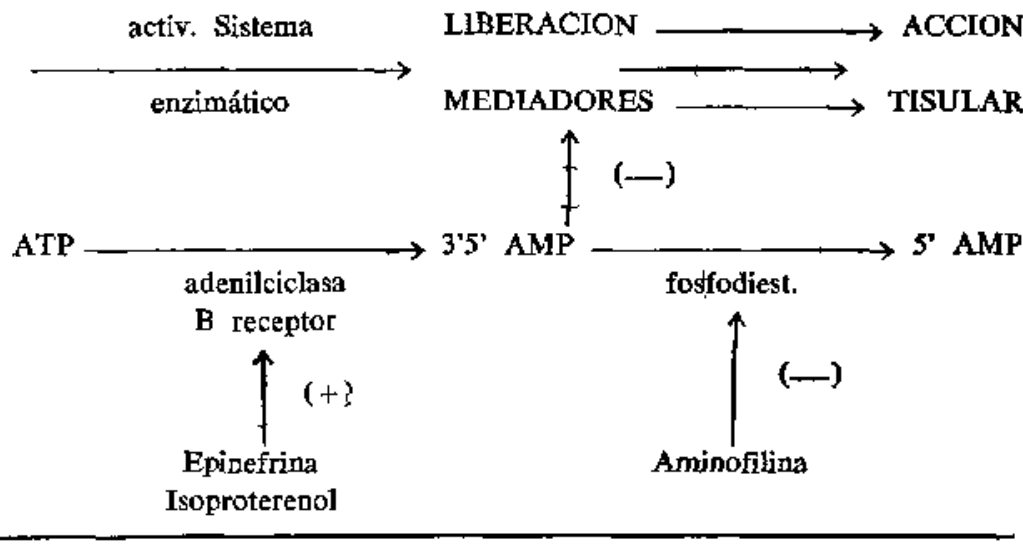


hallazgos de alergia son insuficientes para explicar el cuadro clínico de estos pacientes. Corresponderían aproximadamente a un $15 \%$ de los niños asmáticos estuđiados (7). En nuestra casuística tenemos un porcentaje similar.

Por una parte podría tratarse de una limitación de los métodos rutinarios de testeo para pesquisar alergia; pero esto también nos está señalando que mientras no tengamos un mayor conocimiento acerca de las causas de hiperrreactividad bronquial, es mejor sustituir al término "Asma intrínseco" por el de "Asma de origen no precisado" (7).

\section{BibLIOGRAFía}

1.-Mathison D. A. "Clinical Profiles of Bronchial Asthmn". JAMA., 224: 1134, 1973.

2.-American Thoracic Society. "Chronic Brouchitis, Asthma and Pulmonary Emphysema: A statement by the committee on Diagnostic Standards for Nontuberculous Respiratory Diseases". Am. Rev. Resp. Dis., 85: 762, 1965.

3.-Heimlich E. "Asthmatic Hyperresponsiveness". The Ped. Clin. of N. A. 16: 149, 1969.

4.-Mansmann, H. "Management of the Child with Bronchial Asthma". The Ped. Clin, of N. A. 15: 357, 1968.

5.-Hilman B. C. "The Allergic Child". Ann. Allerg. 25: $620,1967$.
6.- Kantor y Speer. "Characteristics of the Allergic Child". The Allergic Child, Ed. por Speer, Hocbel, New-York, 1963.

7.-Aas, Kiell, "Allergic Asthma in Childhood". Arch. Dis. Child. 44: 1, 1969.

8.-Frek, O. "Mediators of Atopic and Anaphylactic Reactions". The Ped. Clin. of N. A. 16: 95, 1969.

9.-Pearlman, D. "Immunoglobulins and Allergic Disease". The Ped. Clin, of N. A. 16: 118, 1969.

10.- Carrasco, E. y Col. "Mecanismos Inmunológicos en las Enfermedades del Aparato Respiratorio". Arch. Arg. Je Alerg. 10: 16, 1973.

11.--Soerensen, R. y Col. "Enfermedades del Aparato Respiratorio vistas por el Inmonólogo". Rev. Chil. de Ped. 44: 362, 1973.

12.- Szentivanyi, A. "The Beta Adrenergic Theory of the atopic Abnormality in Bronchial Asthma". J. of Allergy, 42: 203-232, 1968.

13.- Lichtenstein and Margolis. "Histamine release in vitro. Inhibition by Cathecolamines and Methilxantines. Science 161: 902, 1968.

14.-Smith and Parker. "The Responsiveness of Leukocyte cyclic AMP to adrenergic agents in pacients with asthma". Proc. Central Soc. Clin. Res. 43: $76,1970$. 